\title{
Determination of the parameters of typical multi-link dimensional chains (closing link is tension) using recurrent dependencies
}

\author{
Sergey Shilyaev ${ }^{1, *}$, Evgeniy Slashchev ${ }^{1}$, Vladimir Osetrov $^{1}$, Igor Voyachek ${ }^{2}$, and Rinat \\ Shaikhov ${ }^{3}$ \\ ${ }^{1}$ Izhevsk State Technical University, 7, Studencheskaya street, Izhevsk, 426069, Russia \\ ${ }^{2}$ Penza State University, 40, Krasnaya street, Penza, 440026, Russia \\ ${ }^{3}$ Perm State Agro-Technological University, 23, Petropavlovskaia street, Perm, 614990, Russia
}

\begin{abstract}
The existing approach to the use of the group interchangeability method during assembly, which are concentrated, has a number of significant drawbacks: 1) there are no formulas for calculating the upper and lower deviations of the component parts of the dimensional chain; 2) deviations are selected without taking into account the design of the component links (the method of equal tolerances is used); 3 ) the method is applicable for the number of links no more than three with a small number of groups. For other types of problems there is no algorithm, mathematical apparatus, and examples of calculation are not considered sequentially; 4) the calculation by the group interchangeability method is limited by the condition of equal tolerances, i.e. excluding compensators and compensating properties of materials as a part of mechanisms; 5) the calculations are based on assumptions about the economic feasibility of increasing the closing link by a factor of $\mathrm{n}$ without taking into account the feasibility of such an increase in the component links that is not permissible in complex mechanisms; 6) the size of the batch of parts and the volume of work in progress are not reflected, as one of the factors of economic feasibility of establishing production tolerance. In this regard, it is necessary to improve the method of achieving accuracy by group interchangeability. This article discusses typical problems that rise when solving dimensional chains in which the closing link is a tension.
\end{abstract}

\section{Introduction}

This article discusses typical problems that rise when solving dimensional chains in which the closing link is a tension. We accept that in the case of tension compared with the gap joints, the diameter of the sleeve is a reducing link, since with increasing it the closing link

\footnotetext{
*Corresponding author: shiljaev@mail.ru
} 
(tension) reduces. The diameter of the shaft in the joint with the tension is an increasing link.

The first problem concerns a three-link dimensional chain. The next two problems concern dimensional chains with one reducing link and two increasing links [1-24].

When solving dimensional chains, the rules set forth in section 1 are applied. Let us consider the solutions with specific examples.

\section{Three-link dimensional chain}

Given: a three-link dimensional chain (Figure 1) and layout of tolerance fields (Figure 2). The method of equal tolerances is applied, the number of groups is $n$. The tolerances of the increasing and reducing links are $T D=T d$. Closing link is a tension. Determine: upper and lower deviations of component parts when applying the method of group interchangeability and the method of equal tolerances.

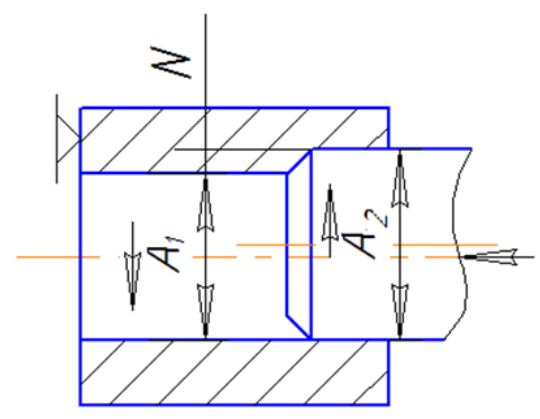

Fig. 1. Dimensional chain when pressing the shaft into the sleeve.

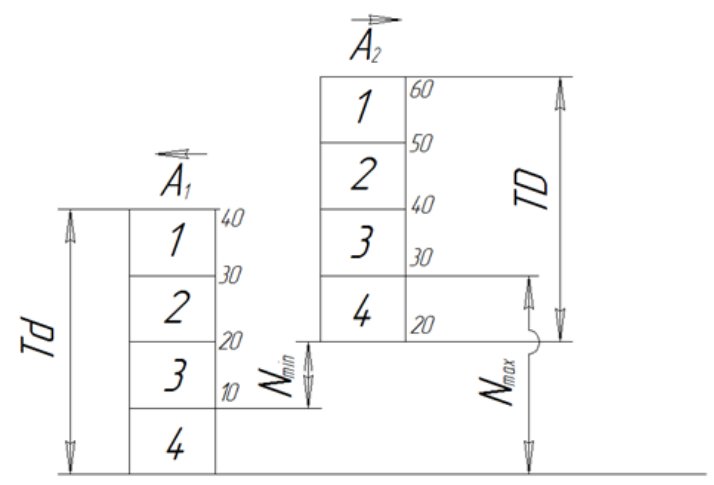

Fig. 2. The layout of tolerance fields when sorting into groups

Based on the induction method for this problem, recurrent formulas are derived for determining the upper and lower deviations of the increasing and reducing links.

For reducing links (Eqs 1,2):

$$
\begin{aligned}
& e s \overleftarrow{A(i)}=T d\left(1-\frac{i-1}{n}\right), \\
& e i \overleftarrow{A(i)}=T d\left(1-\frac{i}{n}\right),
\end{aligned}
$$


where $i=1,2 \ldots n$ - the current variable characterizing the number of groups, $T d$ is the tolerance of the reducing link, since the tension decreases with increasing hole diameter. Upper and lower deviation of the increasing links (Eq 3,4):

$$
\begin{aligned}
& \operatorname{ES~} \overleftarrow{A(i)}=\frac{T D}{n}(2+n-i)+N_{\min }, \\
& E I \overleftarrow{A(i)}=\frac{T D}{n}(1+n-i)+N_{\min },
\end{aligned}
$$

where $N_{\min }$ is minimal tension, TD- the tolerance of the increasing link (the shaft), since with an increase in the diameter of the shaft the tension (closing link) increases.

The calculation was made with the following initial data: $T D=T d=40$ microns, $n=4$. The calculation results for the recurrent formulas are given in Table 1

Table 1. Calculation results (with the tension, microns).

\begin{tabular}{|c|c|c|c|c|c|c|c|}
\hline \multirow{2}{*}{$n$} & \multicolumn{2}{|c|}{ Shaft $-\mathrm{A}_{2}$} & \multicolumn{2}{|c|}{ Sleeve - $\mathrm{A}_{1}$} & \multicolumn{2}{|c|}{ Tension $N$} & \multirow{2}{*}{$T N$} \\
\cline { 2 - 8 } & $E S$ & $E I$ & $e s$ & $e i$ & $\max$ & $\min$ & \\
\hline 1 & 60 & 50 & 40 & 30 & 30 & 10 & 20 \\
\hline 2 & 50 & 40 & 30 & 20 & 30 & 10 & 20 \\
\hline 3 & 40 & 30 & 20 & 10 & 30 & 10 & 20 \\
\hline 4 & 30 & 20 & 10 & 0 & 30 & 10 & 20 \\
\hline
\end{tabular}

\section{A multi-link dimensional chain with a tension. The method of equal tolerances}

Given: connection of parts in the form of a multi-link dimensional chain with a tension (fig. 3 , for example, 1 - bracket, 2, 3 - covered bus leads) and the arrangement of tolerance fields (fig. 4). The method of equal tolerances is used, the number of groups is $n$, the number of increasing links sorted into groups $m_{\text {inc }}=2$. The layout in fig. 3 is a typical one and reflects the second rule for the arrangement of tolerance fields, for which the middle coordinates of the closing link and the component links are equal.

Determine: the upper and lower deviations of the component links when applying the group interchangeability method and the equal tolerance method. We determine the upper and lower deviations of the reducing link according to Eqs. 1, 2. For the upper and lower deviations of the increasing links, analyzing the layout (Figure 4), we derive the recurrent Eqs. 5,6 by the induction method:

$$
\begin{aligned}
& \operatorname{ES} \overrightarrow{A(i, j)}=\left(T d / n+N_{\min }\right) \frac{\prod_{k=2}^{m}\left(k-\left(j-m_{\text {red }}\right)\right)}{(m-1) !}+\frac{T D}{m_{i n c}}\left(1-\frac{(i-1)}{n}\right), \\
& E I \overrightarrow{A(i, j)}=\left(T d / n+N_{\min }\right) \frac{\prod_{k=2}^{m}\left(k-\left(j-m_{\text {red }}\right)\right)}{(m-1) !}+\frac{T D}{m_{i n c}}\left(1-\frac{(i)}{n}\right)
\end{aligned}
$$

where $j=1,2 \ldots m ; k=2,3 \ldots m_{\text {red }}$ - current variables corresponding to the number of component links $(m \geq 2)$. 


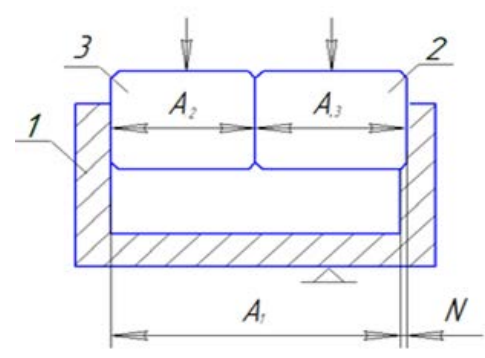

Fig. 3. Dimensional chain of connecting parts (1-bracket, 2,3-bus leads covered).

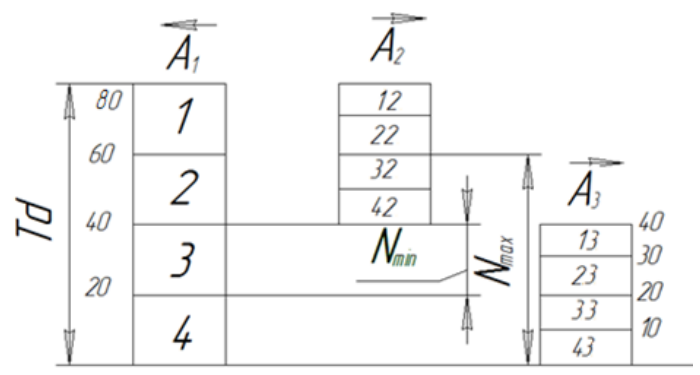

Fig. 4. The layout of tolerance fields for group interchangeability (two magnifying links with equal tolerances)

In Eqs. 5 and 6 the product with $m_{\text {red }}=1, m=3, j=2,3$ is determined as follows:

$$
\frac{\prod_{k=2}^{m}\left(k-\left(j-m_{\text {red }}\right)\right)}{(m-1) !}=\frac{(2-(2-1)) \cdot(3-(2-1))}{2 \cdot 1}=1
$$

The calculation was made with the following initial data: $n=4, T d=80$ microns, Nmin $=20$ microns, $N \max =60$ microns. The calculation results are given in the Table 2 .

The formulas (5) and (6) are applied when the nominal sizes of the links are in the same interval of the normal series of numbers, i.e. tolerances for all increasing links are equal.

Table 2. Problem solution results (with tension, microns) .

\begin{tabular}{|c|c|c|c|c|c|c|c|c|c|}
\hline \multirow{2}{*}{$\begin{array}{c}\text { Groups } \\
n=4\end{array}$} & \multicolumn{2}{|c|}{$\mathrm{A}_{2}=20$} & \multicolumn{2}{|c|}{$A_{3}=20$} & \multicolumn{2}{|c|}{$A_{1}=40$ reducing } & \multicolumn{2}{|c|}{ Tension $N$} & \multirow[t]{2}{*}{$T N$, } \\
\hline & $\begin{array}{c}\text { Upper } \\
\text { ES A }(i, j)\end{array}$ & $\begin{array}{c}\text { Lower } \\
\text { EI A }(i, j)\end{array}$ & $E S A(i, j)$ & EI A $(i, j)$ & es $A(i, j)$ & $e i A(i, j)$ & $\operatorname{Max}$ & Min & \\
\hline 1 & 80 & 70 & 40 & 30 & 80 & 60 & 60 & 20 & 40 \\
\hline 2 & 70 & 60 & 30 & 20 & 60 & 40 & 60 & 20 & 40 \\
\hline 3 & 60 & 50 & 20 & 10 & 40 & 20 & 60 & 20 & 40 \\
\hline 4 & 50 & 40 & 10 & 0 & 20 & 0 & 60 & 20 & 40 \\
\hline
\end{tabular}

It should be noted that in the manufacture brackets are used for mounting tires and boxes with wires. If the tension is greater than permissible, then there may be a breakdown of the bracket. Therefore, the sizes are sorted according to the Table 2. 


\section{A multi-link dimensional chain with a tension. The method of equal accuracy is applied}

Given: multi-link dimensional chain. Two increasing links $m_{i n c}=2$ and one reducing link (Figure 5). The layout of tolerance fields is given in Figure 6. The sums of the tolerances of the increasing and reducing links are equal. The method of equal accuracy is applied. The number of groups is $n$.

Determine: upper and lower deviations of the component parts when applying the method of group interchangeability and the method of equal accuracy.

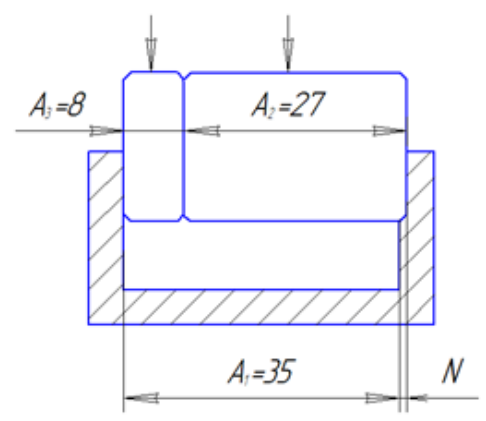

Fig. 5. Multi-link dimensional chain.

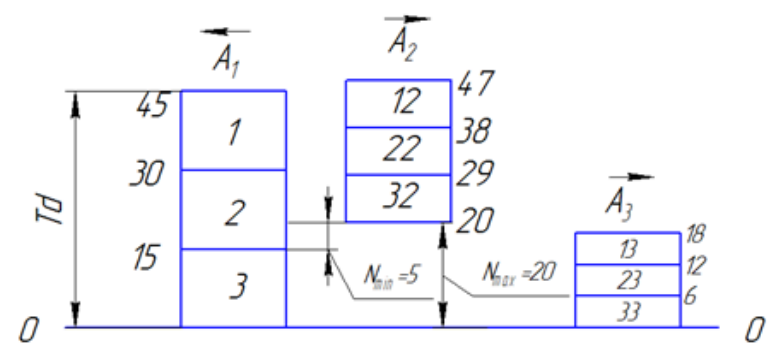

Fig. 6. The layout of tolerance fields for group interchangeability (two increasing links with different tolerances)

First, we derive formulas for determining the tolerances of the increasing links (Eq.8):

$$
T(i, j)=a \cdot e_{j}
$$

$T(i, j)$ - the tolerance for the size of the increasing link;

$a$ - the number of tolerance units (Eq.9):

$$
a_{j}=\frac{T d}{n \cdot \sum_{j=1}^{m_{i n c}} e_{j}}=\frac{T d}{n \cdot\left(e_{1}+e_{2}+\ldots+e_{m_{i n c}}\right)},
$$

where $e_{j}$ is the tolerance unit determined using the Eq. 10 .

$$
e_{j}=0,45 \sqrt[3]{A_{j}}+0,001 A_{j}
$$


Then, by induction using the layout in Figure 6, we determine the recurrent dependencies to determine the upper and lower deviations of the increasing links (Eqs. 11,12):

$$
\begin{gathered}
\operatorname{ES} \overrightarrow{A(i, j)}=\left(T d / n+N_{\min }\right) \frac{\prod_{k=2}^{m}\left(k-\left(j-m_{y M}\right)\right)}{(m-1) !}+T(i, j) \cdot n \cdot\left(1-\frac{(i-1)}{n}\right), \\
E I \overrightarrow{A(i, j)}=\left(T d / n+N_{\min }\right) \frac{\prod_{k=2}^{m}\left(k-\left(j-m_{r e d}\right)\right)}{(m-1) !}+T(i, j) \cdot n \cdot\left(1-\frac{(i)}{n}\right),
\end{gathered}
$$

where $\mathrm{m}$ is the number of component links.

The calculation was made with the following initial data: $A_{2}=27 \mathrm{~mm} ; A_{3}=8 \mathrm{~mm} ; A_{1}=$ $35 \mathrm{~mm} ; \mathrm{Td}=\mathrm{TD}=45$ microns; $N_{\max }=20$ microns, $N_{\min }=5$ microns; $\mathrm{n}=3, \mathrm{~m}_{\text {inc }}=2$ is the number of increasing links sorted into groups; $T_{g r}=15$ microns - group tolerance of the reducing link.

The tolerance units are determined by the formula 9 for the increasing links: $A_{2}=27 \mathrm{~mm}$ и $\mathrm{A}_{3}=8 \mathrm{~mm}$ :

$e_{2}=0,45 \sqrt[3]{27}+0,027=1,35$ microns; $e_{3}=0,91$ microns.

The number of tolerance units is calculated using the formula 10 :

$$
a=T d / 3 \cdot \sum_{j=1}^{m} e_{j}=45 / 3 \cdot(1,35+0,91)=6,63 \text {; }
$$

Group tolerances for incremental links are determined (with rounding):

$$
\begin{aligned}
& T(1,2)=T(2,2)=T(3,2)=a \cdot e_{2}=6,63 \cdot 1,35 \cong 9 \text { microns; } \\
& T(1,3)=T(2,3)=T(3,3)=a \cdot e_{3}=6,63 \cdot 0.91 \cong 6 \text { microns }
\end{aligned}
$$

The upper and lower deviations of the reducing links are determined by the Eqs. 1,2, and the deviations of the increasing links - by the formulas (11) and (12).

The results of solvation of the problem are given in table 3 .

Table 3. The results of solvation of the problem with tension (microns)

\begin{tabular}{|c|c|c|c|c|c|c|c|c|c|}
\hline \multirow{2}{*}{$\begin{array}{c}\text { Groups } \\
(n=3)\end{array}$} & \multicolumn{2}{|c|}{$\mathrm{A}_{2}=27 \mathrm{~mm}$} & \multicolumn{2}{|c|}{$\mathrm{A}_{3}=8 \mathrm{~mm}$} & \multicolumn{2}{|c|}{$\mathrm{A}_{1}=35 \mathrm{~mm}$} & \multicolumn{2}{|c|}{ Tension $N}$, & $T N$ \\
\cline { 2 - 10 } & $E S$ & $E I$ & $E S$ & $\begin{array}{c}\text { EI } \\
\text { microns }\end{array}$ & $\begin{array}{c}\text { es } \\
\text { microns }\end{array}$ & $\begin{array}{c}e i \\
\text { microns }\end{array}$ & max & min & \\
\hline 1 & 47 & 38 & 18 & 12 & 45 & 30 & 30 & 5 & 15 \\
\hline 2 & 38 & 29 & 12 & 6 & 30 & 15 & 30 & 5 & 15 \\
\hline 3 & 29 & 20 & 6 & 0 & 15 & 0 & 30 & 5 & 15 \\
\hline
\end{tabular}

\section{Conclusion}

The presented typical problems using the obtained recurrent dependencies reveal dimensional bonds in multilink chains in which the closing link is the tension when applying the group interchangeability method. The tables with the calculation results are the main part of the technological document for sorting parts into groups during assembly. 


\section{References}

1. Anurev V.I. (2001) Reference book for designer-mechanical engineer: In 3 v. V.2. 8-th ed., rev. and add.; Ed. I.N. Zhestkova. Moscow: Mashinostroenie, 2001, 912 p., Russia.

2. Kolesov, IM (1999) Fundamentals of mechanical engineering technology: a textbook. 2nd ed., Corr. Moscow: Higher. school. Russia.

3. Nepomiluev V.V., Oleynikova E.V., Gusarova N.I. (2015) Probabilistic-statistical model of the process of individual selection. Intelligent systems in production 1: 8-13, Russia.

4. Osetrov V.G., Slashchev E.S. (2015) Assembly in mechanical engineering, instrument making. Theory technology and organization. Izhevsk. IICP

5. Osetrov V.G., Slashchev E.S. (2014) Improving the calculations of the dimensional chain when using the method of group interchangeability. Assembly in mechanical engineering, instrument making 7: 24-29, Russia.

6. Osetrov V.G., Slashchev E.S. (2014) The calculation of the accuracy of compounds with tension when using the method of group interchangeability. Intelligent systems in production. 2 (24): 5256, Russia.

7. Scholz, F. (1995) Tolerance Stack Analysis Methods Research and Technology. Boeing Information \& Support Services.

8. Sorokin M.N., Anurov Y.N. (2011) Formalization of the method of intergroup interchangeability in the implementation of selective assembly of products. Assembly in mechanical engineering, instrument making 8: 16-19, Russia.

9. Sorokin M.N., Anurov Y.N. (2016) Rolling bearing assembly. Assembly in mechanical engineering, instrument making. 2:18-23, Russia.

10. Lebedevsky M.S., Weitz V.L., Fedorov A.I. (1985) Scientific basis of automatic assembly. Moscow: Mashinostroenie, Russia.

11. Altschul R. (1994) Case study in statistical tolerancing. Manufacturing Review of the AMSE 7: 52-56.

12. Bezyazyachny V.F., Nepomiluyev V.V. (2015) Possible ways to improve the quality of manufacturing engineering products. Assembly in mechanical engineering, instrument making 1: 17-20, Russia.

13. Chase, K.W., Gao, J., Magleby, S.P., Sorensen, C.D. (1996) Including geometric feature variations in tolerance analysis of mechanical assemblies. IE Transactions (Institute of Industrial Engineers) 28 (10): 795-807.

14. Goldfarb, V., Malina, O., Trubachev, E (2016) New concept of the process of designing gearboxes and gear systems. Mechanisms and Machine Science 34: 405-423.

15. Henzold, G. (2006) Geometrical dimensioning and tolerancing for design Manufacturing and Inspection. 2nd Edition - Elsevier.Oxford, UK

16. Laaneots R. (2004) Modified calculation method of tolerance of dimensional chain dependent link. $4^{\text {th }}$ international DAAAM symposium «Industrial engineering - innovation as competitive edge SME» Tallinn, Estonia:. 43-46.

17. Mishunin V.P. Osetrov V.G. (2002) Optimization in achieving the accuracy of the axial clearance in the gearboxes. Assembly in mechanical engineering, instrument making. 2002, №6, P. 2-4, Russia.

18. Srinivasan V. (2008) Standardizing the specification, verification, and exchange of product geometry Research, status and trends. Computer-Aided Design 40 (7): 738-749.

19. Sun Y., Gupta M. (2004) Optimization of a flat due. Mechanical Engineering - Engineering Mechanics Department Michigan Technological University Houghton, ANTEC: 3007-3011.

20. Voyachek I.I. (2006) Integrated design of fixed couplings: monograph. Penza: Penza State University, Russia.

21. Malikova, D.M., Slashchev, E.S., Istomin, E.P., Vagizov, M.R., Kolbina, O.E. (2020) Method for solving problems of the theory restrictions of infocommunication systems using linear equations with many unknowns. IOP Conference Series: Earth and Environmental Science, 2020, 507(1), 012018 .

22. Shilyaev, S., Slashchev, E., Mikhaylov, Y. (2020) The method for achievement of group interchangeability accuracy for multilink dimension chains with gaps. IOP Conference Series: Materials Science and Engineering, 2020, 709(2), 022033. 
23. Voyachek, I.I., Slashchev, E.S., Malikova, D.M. (2020) Feasibility Study of Applying Group Interchangeability Method for Assembly Components of Machines. Lecture Notes in Mechanical Engineering, 2020, c. 271-280.

24. Osetrov, V.G., Slashchev, E.S., Malikova, D.M., Shilyaev, S.A., Shaikhov, R.F. (2020) Deterministic approach to reducing the labor intensiveness and enterprises product lifecycle cost management. Journal of Advanced Research in Dynamical and Control Systems, 2020, 12(2 Special Issue), c. 391-395. 